[in press, American Journal of Human Biology, October 2015]

\title{
Does Human Ejaculate Quality Relate to Phenotypic Traits?
}

Austin John Jeffery ${ }^{1}$, Michael N. Pham ${ }^{1}$, Todd K. Shackelford ${ }^{1}$, and Bernhard Fink ${ }^{2}$

1. Department of Psychology, Oakland University, Rochester, MI, 48307

2. Institute of Psychology and Courant Research Center Evolution of Social Behavior, University of Göttingen, Göttingen, Germany

Send correspondence to Austin John Jeffery at ajjeffer@oakland.edu. 


\begin{abstract}
A given man's phenotype embodies cues of his ancestral ability to effectively defend himself and his kin from harm, to survive adverse conditions, and to acquire status and mating opportunities. In this review, we explore the hypothesis that a man's phenotype also embodies cues to fertility, or the probability that an ejaculate will fertilize ova. Female mate choice depends on the ability to discern the quality of a male reproductive partner through his phenotype, and male fertility may be among the traits that females have evolved to detect. A female who selects as mates males that deliver higher quality ejaculates will, on average, be more fecund than her competitors. Data on several non-human species demonstrate correlations between ejaculate quality and secondary sexual characteristics that inform female mate choice, suggesting that females may select mates in part on the basis of fertility. While the non-human literature on this topic has advanced, the human literature remains limited in scope and there is no clear consensus on appropriate methodologies or theoretical positions. We provide a comprehensive review and meta-analysis of this literature, and conclude by proposing solutions to the many issues that impede progress in the field. In the process, we hope to encourage interest and insight from investigators in other areas of human mating and reproductive biology.

Keywords: sexual selection, fertility, mate value, meta-analysis, sperm competition
\end{abstract}




\section{Does Human Ejaculate Quality Relate to Phenotypic Traits?}

\section{Introduction}

Sexual selection produces adaptations in males that function to increase the likelihood of securing copulations (pre-copulatory selection) and to increase the likelihood that those copulations result in fertilizations (post-copulatory selection; Andersson and Simmons, 2006). In pre-copulatory selection, males (typically) compete against other males (intrasexual competition) to secure copulations from choosy females (intersexual competition; Parker et al., 2011). Females favor mating with high-quality males, and make these discriminations by attending to variations in male morphology and behavior (for reviews, see Mays and Hill, 2004; Price et al., 1993).

A growing literature highlights the significance of post-copulatory sexual selection in human evolution (Baker and Bellis, 1995; reviewed in Pham and Shackelford, 2014). Women's reproductive tracts are generally inhospitable for parasites and pathogens (e.g., low $\mathrm{pH}$, heightened immune responses), but also for sperm (Birkhead et al., 1993; Moyer et al., 1970; Suarez and Pacey, 2006). Thus, this environment selects for higher-quality sperm that are better able to fertilize ova by virtue of abundance, durability, motility, etc. (for a review, see Wira et al., 2010). Additionally, sperm competition may influence ejaculate quality by generating selection pressures to outcompete rival ejaculates in the female reproductive tract (Baker and Bellis, 1989, 1993a, 1993b, 1995; Shackelford and Pound, 2006; Shackelford et al., 2005). However, the competitiveness of an ejaculate is not identical to its fertility. A competitive ejaculate may be competitive not because it can fertilize ova, but because it reduces the probability that rival sperm fertilize ova (e.g., toxins in semen that harm a female, but dissuade her from mating with other males; Johnstone and Keller, 2000). That said, recurrent ancestral exposure to sperm competition is expected to promote fertility in male lineages.

Studies have documented relationships between men's ejaculate quality and phenotypic traits that women find attractive, including facial attractiveness, body symmetry, and intelligence (see Table 1). One explanation for such relationships is a general fitness factor, which predicts positive correlations among traits that contribute to survival and reproduction-including ejaculate quality (Houle, 2000). In this view, 
correlations between ejaculate quality and the phenotypic traits that women find attractive are byproducts of their shared correlation with a third, underlying variable (e.g., developmental stability, parasite load, mutation load; see Pierce et al., 2009). Another explanation is that a preexisting correlation between phenotypic traits and ejaculate quality may have selected for adaptations in human female mating psychology to detect and capitalize on the reproductive benefits afforded by a high-quality ejaculate. Thus, a correlation with ejaculate quality may represent one of many reasons that particular phenotypic traits are found attractive. A woman seeking reproductive opportunities could benefit from attending to any phenotypic traits that reliably cue a man's ejaculate quality. Ancestral women who found more fertile men more sexually attractive would have out-reproduced women with different preferences. It could also benefit men who are capable of producing high-quality ejaculates to signal this ejaculate quality to women. Such a signal would facilitate matings with women who discriminate for effective ejaculates, allowing the couple to produce sons with competitive sperm and daughters who discriminate on the basis of fertility. However, because there is no evidence of adaptations in men designed to advertise ejaculate quality, we use the (passive) term "cue" rather than the (active) term "signal" with reference to humans.

Ten percent of sexually active heterosexual couples are infertile (Mosher, 1985) in both developed and developing countries (Boivin et al., 2013). Low-quality ejaculate is independently responsible for about $20 \%$ of these cases, and contributes to another $27 \%$ of cases in which male and female factors interact (World Health Organization, 1987). Modern factors contribute to reduced male fertility (e.g., exposure to chemicals and modern dietary habits; Povey et al., 2012; Tielemans et al., 1999; Mendiola et al., 2009) and it will remain unknown what percentage of men across our ancestral history experienced difficulty fertilizing ova. However, research demonstrates that male infertility is largely attributable to genetic differences (Ferlin et al., 2007; O’Flynn O’Brien, Varghese, \& Agarwal, 2010), suggesting that there have long existed polymorphisms vulnerable to disruptions in spermatogenesis. To be clear, we will review evidence for and against the hypothesis that phenotypic traits provide information about ejaculate quality in fertile men, and not that phenotypic traits distinguish fertile men from infertile men. 
Ejaculate quality is not detectable directly (without a microscope), but may be assessed indirectly from other observable traits. The phenotype-linked fertility hypothesis (PLFH) proposes that females assess male fertility through secondary sexual characteristics (SSCs) that provide honest cues of a male's probability of fertilizing ova (Sheldon, 1994). The PLFH thus links pre-copulatory selection with postcopulatory selection, with females making pre-copulatory mate choices based on phenotypic markers of post-copulatory fitness (see Mautz et al., 2013, for review). When the PLFH was originally advanced, Sheldon (1994) suggested that females acquire extra-pair partners who display cues of fertility as insurance against the infertility of their regular partner. In humans, women typically seek extra-pair copulations with men who display more desirable traits (e.g., health, attractiveness, dominance) than their regular partner (Pillsworth and Haselton, 2006). Although the PLFH aligns with the "good genes" hypothesis of female infidelity (i.e., seeking a mate that will produce reproductively successful offspring), it does not exclude the possibility that women also select extra-pair partners who (incidentally) produce higher-quality ejaculates. A broad interpretation of the PLFH predicts that females conduct a phenotypic estimation of ejaculate quality in all or some mate choice calculations, rather than strictly securing insurance against regular partner infertility by pursuing extra-pair copulations.

The literature exploring the relationship between male phenotype and fertility provides mixed results depending on the species and methodology (see section on non-human studies; Mautz et al., 2013), and only a small collection of disparate studies has investigated this relationship in humans. To render this human literature easier to navigate and understand, we review every study that addresses correlations between men's phenotypic traits and ejaculate quality, interpret these findings in the context of female mate choice, and conduct and present the results of a series of meta-analyses. Our review includes studies linking ontogenetically stable phenotypic traits to ejaculate quality, and excludes studies linking evolutionarily novel or ontogenetically unstable traits (smoking, diet, exercise, weight, etc.) to ejaculate quality. All studies on this topic have investigated adults in modern industrialized societies, many of whom are affiliated with universities in East Asia, Western Europe, the United States, and Australia. Table 1 details the studies found in preparation of this review. Throughout, we explore the possibility that 
human female mating psychology is attentive to cues of ejaculate quality displayed in men's observable traits. These studies test the hypothesis that trait attractiveness positively correlates with ejaculate quality. As we will argue, there are theoretical and empirical reasons to doubt positive relationships between human ejaculate quality and many traits. The direction of the relationship between phenotype and ejaculate quality is irrelevant to the hypothesis that women use phenotype to infer ejaculate quality, as long as there is some consistent relationship with ejaculate quality for any given phenotypic trait. After addressing the state of the human literature and reporting the results of the meta-analyses, we turn briefly to the non-human literature, and close with a discussion of how to improve future research in this area. The body of this review underlines problems that exist in the literature, leaving it until the conclusion to propose solutions to those problems.

\section{Human Studies}

\section{Facial attractiveness}

Facial attractiveness may honestly advertise good health and, thus, mate value (for a review, see Thornhill and Gangestad, 1999a). Women's attraction to particular male facial traits may motivate them to mate with males that produce high-quality ejaculates. In a Spanish sample, men's facial attractiveness — as rated by women — correlated positively with sperm motility, sperm morphology, and sperm concentration (Soler et al., 2003). These findings were replicated in research that secured Spanish and Colombian women's assessments of Spanish men's facial attractiveness (Soler et al., 2014). Soler et al. (2014) also found that measurements of men's cheekbone width - a trait linked with testosterone, aggressiveness, dominance, and status (Lefevre et al., 2013) — correlated negatively with ejaculate quality. In an Australian sample, the same three semen parameters were not correlated with women's ratings of men's facial and body attractiveness, or with women's ratings of facial and body masculinity, averageness, or symmetry (Peters, Rhodes, and Simmons, 2008). However, whereas women's ratings of traits such as symmetry and masculinity can be compared to objective measurements, facial attractiveness is a subjective trait in these studies and is not objectively verifiable. One result of this is that a woman can be inaccurate in her report of facial symmetry, but still rate more symmetrical men to be more attractive. 
This kind of report bias may explain why the objective measure of facial masculinity (e.g., cheekbone width), but not the subjective reports of facial masculinity, correlated with ejaculate quality (Peters et al., 2007; Soler et al., 2014).

The different results among these studies may be attributable to methodological differences. Soler et al. $(2003,2014)$ asked women to report their interest in a long-term relationship with the photographed male, whereas Peters et al. (2007) asked women to report their short-term sexual interest in the photographed male. These different contexts influence the traits that women find attractive, with a priority on masculinity in short-term contexts but not in long-term contexts (Li and Kenrick, 2006; Little et al., 2002; Soler et al., 2012). No a priori hypotheses provide a clear prediction for the mating context in which a woman's sensitivity to fertility should be more acute. In short-term sexual relationships, there may be greater pressure to achieve fertilization from fewer copulations (e.g., during a one-night stand). Because the woman might only gain indirect benefits from short-term relationships (e.g., high-quality genes), she may seek short-term partners who produce higher-quality ejaculates (for lack of direct benefits like resources and protection that are more often acquired in long-term relationships; Gangestad and Simpson, 2000). The opposite hypothesis is also defensible, because a woman in a long-term relationship with a man who produces lower-quality ejaculates will incur reproductive costs, particularly if the man effectively guards against her infidelity. If women prefer fertility-linked traits in long-term contexts more than in short-term contexts, then the risk of low-fertility long-term partners may have had greater relevance in human evolutionary history. That is, women may incur more costs when mating with a man who produces lower-quality ejaculates in long-term contexts than in short-term contexts and, therefore, women find facial traits that are positive correlates of ejaculate quality more attractive in longterm than in short-term partners. In these scenarios, a negative correlation between phenotype and fertility (i.e., more attractive men produce lower-quality ejaculates) would generate the same competing considerations in female mate choice, because it is only the relative difference in men's fertility, as signaled by their phenotype, that is relevant. 
Leivers, Rhodes, and Simmons (2014) found that an aggregate of men's attractiveness, dominance (both rated by women), and self-perceived mate value correlated positively with their masturbatory ejaculate quality, but only when they produced the ejaculate while viewing images of highly attractive women. There was no correlation between men's mate value and their ejaculate quality when the ejaculate was produced while viewing low attractiveness women. Thus, men with attractive phenotypic traits may produce higher-quality ejaculates when copulating with an attractive woman and, potentially, when at greater sperm competition risk (Goetz et al., 2005; Pham and Shackelford, 2013; Pham et al., 2014; Shackelford et al., 2002, 2007). Leivers et al. argue that future studies in this area must account for the context in which men ejaculate because the perceived mate value of both men and women influences the quality of the ejaculate. The researchers also noted that if they ignored female attractiveness in their study, then they would have produced inconsistent results depending on the use of masturbatory stimulus.

\section{Fluctuating Asymmetry}

Developmental perturbations in utero and in early life can produce fluctuating asymmetries (FA) in bilateral traits and indicate poor developmental conditions, poor health, and perhaps poor heritable immunocompetence (Van Dongen and Gangestad, 2011). Thus, FA may provide information about male genetic quality (Gangestad et al., 1994). For example, women are more attracted to men with more symmetrical faces (Thornhill and Gangestad, 1999b; Grammer and Thornhill, 1994), and women rate men with lower body FA as having more attractive faces (Gangestad et al., 1994). Sperm motility, morphology, and concentration are not correlated with subjective measures of men's facial symmetry (Peters et al., 2007), but are correlated with objective measures of symmetry. Manning, Scutt, and LewisJones (1998a) found that FA across the second, third, fourth, and fifth fingers correlates negatively with sperm number, average sperm speed, and sperm speed migration performance (i.e., more symmetrical hands are associated with higher-quality ejaculates). Firman et al. (2003) constructed a composite measure of body FA from measurements of ear length, wrist diameter, elbow diameter, ankle diameter, foot length, foot width, and the lengths of the second and fourth fingers, and found that body FA 
correlates negatively with sperm number, sperm motility, and sperm head length. Finally, Baker (1997) found that a composite measure of body FA (second finger length, ear length, wrist width, and ankle width) correlates negatively with sperm number.

Baker (1997) argued that men with lower FA—relative to men with higher FA—produce more competitive ejaculates because they have more sexual partners and, therefore, consistently experience higher levels of sperm competition (Thornhill and Gangestad, 1994; cf. Simmons et al., 2004). This is consistent with the prediction that ejaculate quality is reflected in male phenotype, and suggests that an evolutionary history of sperm competition may account, in part, for the correlations between FA, sexual attractiveness, and ejaculate quality. In fact, it has been suggested that women have historically encouraged sperm competition by mating multiply, increasing the chance that their ova are fertilized by the man with the most competitive ejaculate (Bellis and Baker, 1995; Nummi and Pellikka, 2012).

\section{D:4D Ratio}

$2 \mathrm{D}: 4 \mathrm{D}$, i.e., the ratio of the length of the second finger (index finger) to the fourth finger (ring finger), is a sexually dimorphic trait with men having lower 2D:4D than women, on average (Manning, 2002). Prenatal hormones influence 2D:4D (Zheng and Cohn, 2011), and finger growth and testes development are both prenatally influenced by Hox genes (Hoxa and Hoxd groups; Herault et al., 1997; Peichel et al., 1997). Disruption at these loci could be responsible for associations between ejaculate quality and digit ratio. Although research has shown that hand features are relevant to female perceptions of male attractiveness and mate value (Koscinski, 2011, 2012; Saino, Romano, and Innocenti, 2006), when 2D:4D is independently assessed in digitally manipulated images, no relationship is found with perceived hand attractiveness (Koscinski, 2011). Thus, 2D:4D is not likely to be a phenotypic cue that women attend to directly, and our discussion of 2D:4D is limited to the sense in which it provides a widely-measured proxy for developmental androgenization (i.e., testosterone exposure; Lutchmaya, Baron-Cohen, Raggatt, Knickmeyer, and Manning, 2004; Manning and Taylor, 2001). Naturally occurring testosterone is not only necessary for spermatogenesis (Walker, 2009), but higher circulating testosterone is associated with improved spermatogenesis (Parapanov, Nussle, Crausaz, Senn, Hausser, \& 
Vogel, 2009) and with increased sexual attractiveness in humans (Sadalla, Kenrick, and Vershure, 1987). Indeed, exogenously administered testosterone — which reduces natural testosterone levels — has been linked with impaired sperm production (Sjögren and Gottlieb, 2001). Women's ovulatory cycle status moderates their attraction to testosterone-linked traits (Roney and Simmons, 2008). Women at high fertility are more attracted to testosterone-linked traits than are women at low fertility (Gildersleeve et al., 2014; Penton-Voak and Perrett, 2000).Women also find men with lower 2D:4D to have more attractive faces and husbands and wives have positively correlated 2D:4D ratios, suggesting that 2D:4D correlates with phenotypic traits that inform assortative mate choices (Ferdenzi et al., 2011; Voracek, Dressler, \& Manning, 2007). If women attend to cues of ejaculate quality to inform mate choices, then low 2D:4D may be associated with rated attractiveness because of a shared association with ejaculate quality.

Data on the relationship between 2D:4D and ejaculate quality is equivocal and may depend on ethnicity. In a Danish sample, 2D:4D was positively correlated with total sperm count (contrary to the prediction that more masculine 2D:4D would correlate with higher-quality ejaculate), but only among men who had a 2D:4D less than or equal to 1.0 (Bang et al., 2005). In a Chinese sample, 2D:4D was negatively correlated with sperm motility among infertile men, but not among fertile men (Lu et al., 2012). Conversely, in a French sample, 2D:4D was negatively correlated with sperm number among fertile men, but not among infertile men (Auger and Eustache, 2010). Auger and Eustache (2010) also measured testes volume among fertile men and found it to be negatively correlated with 2D:4D. Manning, Scutt, Wilson, and Lewis-Jones (1998b) found that testosterone level, sperm number, ejaculate size, and average sperm swimming speed correlated negatively with 2D:4D ratio, but only for the right hand. Firman, Simmons, Cummins, and Matson (2003) did not find a correlation between 2D:4D and sperm number, sperm motility, sperm head length, or sperm tail length. Finally, in a South Korean student sample, no significant correlations were identified between 2D:4D and ejaculate volume, sperm number, or percentage of motile sperm (Seo et al., 2010). The regionally scattered evidence for a relationship between 2D:4D and fertility may be related to the finding that 2D:4D ratios vary by ethnicity, with 
differences between men from different populations being greater than sex differences within populations (Manning, 2002). This may be related to ethnic differences in circulating testosterone (Lynn, 1990).

Intelligence

Intelligence is important in assessments of human mate value (Prokosch et al., 2009) because it represents an ability to solve adaptive problems (Cosmides and Tooby, 2001). Women highly value intelligence in potential long-term mates (Feingold, 1992; Li, Bailey, Kenrick, and Linsenmeier, 2002) and short-term mates (Haselton and Miller, 2006). If men's intelligence is linked with ejaculate quality, then women who select intelligent men as mates are thereby selecting men who produce high-quality ejaculates. Arden, Gottfredson, Miller, and Pierce (2008) found that men with higher general intelligence produced ejaculates with greater sperm numbers, greater sperm concentration, and a greater percentage of motile sperm. Pierce et al. (2009) suggested that polyunsaturated fatty acids could simultaneously influence cognitive ability and ejaculate quality. Polyunsaturated fatty acids are critical to both neurodevelopmental function and spermatogenesis (Barcelo-Coblijn et al., 2003; Lenzi et al., 2000). Mutations in genes that influence the production of these fatty acids may explain the correlation between intelligence and ejaculate quality. Other studies have found negative correlations between intelligence and FA (i.e., more intelligent men are more symmetrical; Furlow et al., 1997; Prokosch et al., 2005; Luxen and Buunk, 2006), and positive correlations between intelligence and longevity (Batty et al., 2007). These findings support the hypothesis of an underlying general fitness factor (see Haselton and Miller, 2006).

\section{Voice Pitch}

Low voice pitch in men is rated as more masculine and attractive by women (Collins, 2000; Feinberg et al., 2005), and men with lower voice pitch report more sexual partners and more offspring (Apicella et al., 2007; Hodges-Simeon et al., 2011; Hughes et al., 2004). Women may have evolved to prefer lower voice pitch because it correlates with larger body size, higher level of circulating testosterone, greater upper body strength, and perceived social dominance (Jenkins, 1998; Evans et al., 2006; Puts et al., 2012). However, direct evidence indicates that men's voice pitch does not correlate with sperm motility or sperm concentration (Simmons et al., 2011). Simmons et al. (2011) also found that men 
with more attractive (but not necessarily lower pitch) voices have lower sperm concentrations, suggesting a tradeoff between investment in attractive phenotypic traits (e.g., lower voice pitch) and investment in ejaculate quality. In several species, sexually dominant males produce ejaculates with lower sperm concentrations, both across the lifespan and conditionally, when dominance is acquired (cockroaches: Montrose et al., 2008; salmon: Pitcher et al., 2009; bustard bird: Preston et al., 2011; crickets: Simmons et al., 2010). The correlation between social dominance and attractiveness (von Rueden et al., 2010) suggests that males who are highly attractive experience less pressure to fertilize ova during any given copulation because they have more opportunities to copulate with any given female. Attractive men may thus be able to afford to invest less in each ejaculate, whereas unattractive men make each copulation count. Furthermore, highly attractive men may experience lower sperm competition risk than less attractive men and, therefore, can invest fewer resources into producing higher-quality ejaculates. Indeed, women who perceive their regular partner to be unattractive also report greater interest in copulating with other men (Gangestad et al., 2005) and report that their regular partner performs more mate guarding behaviors (Pillsworth and Haselton, 2006).

\section{Meta-Analysis}

We performed a series of meta-analyses to characterize the distribution of effects produced by the studies described above (and listed in Table 1). For each set of analyses, we used the random effects model described by Hedges and Olkin (1985). This technique begins by converting effect sizes into $z$ scores (Fisher transformation), calculating an appropriate weight for each $z$-score based on within-study and between-study variability, calculating the mean and standard error of these weighted scores (denoted $\bar{Z}$ and $S E$ ), and computing the probability of observing that mean given the null hypotheses that the mean effect size is zero (to produce a $p$ value). We use the random effects model rather than the fixed effects model due to the expectation of heterogeneity in each set. Heterogeneity is here reported in the form of the $I^{2}$ statistic, which indicates the percentage of total variance in a set of effect sizes that is attributable to between-study variance, as defined by Higgins and Thompson (2002). The full set of 14 studies included three samples of infertile men drawn from fertility clinics. We excluded data from clinical samples from 
our analyses because we wanted to assess the hypothesis that subclinical variance in male fertility is predicted by variance in phenotypic traits.

Our first two analyses explored the relationship between the percentage of motile sperm and two sets of distinct phenotypic traits: 2D:4D and attractiveness/fluctuating asymmetry. Studies of attractiveness and fluctuating asymmetry were combined into one analysis because attractiveness and symmetry are strongly correlated (as factors related to mate choice; Peters, Rhodes, and Simmons, 2007; Scheib, Gangestad, and Thornhill, 1999) and because separate meta-analyses would only include two and three studies. For the same reasons, we included two studies that assessed correlations between attractiveness and composite measures of ejaculate quality (in both studies reporting composite measures of ejaculate quality, sperm motility was among the traits with the largest factor loadings; Leivers et al., 2014; Soler et al., 2014). Sperm motility was selected because it is the one ejaculate parameter that is common across each study and because it is strongly linked with fertilization success (Donnelly, Lewis, McNally, and Thompson, 1998; Hirano et al., 2001). The mean weighted effect size of the relationship between 2D:4D and percentage of motile sperm across four studies was $\bar{Z}=0.019, S E=0.041, p>0.05$, $I^{2}=0 \%$. The mean weighted effect size of the relationship between attractiveness/fluctuating asymmetry and percentage of motile sperm (including two studies with composite measures) across five studies was $\bar{Z}=0.241, S E=0.107, p=0.012, I^{2}=74 \%$. The set of 2D:4D studies demonstrated homogeneity, indicating that there was no significant contribution of between-study variance to the calculation of the mean effect; however, the mean effect was non-significant. In contrast, the set of attractiveness/ fluctuating asymmetry studies demonstrated significant between-study variance and produced a significant mean effect. These findings indicate that the relationship between 2D:4D and sperm motility is consistently measured but non-significant, whereas the relationship between factors related to mate choice and sperm motility is inconsistently measured, but significant.

To further probe the relationship between phenotype and individual ejaculate parameters, we performed three further meta-analyses investigating the mean effect of all measured phenotypic traits on the percentage of motile sperm (eight studies), sperm concentration (six studies), and sperm count (five 
studies). Collapsing across phenotypes is consistent with the concept of a general fitness factor that influences phenotypes broadly (e.g., androgenization reduces 2D:4D, increases attractiveness, and improves ejaculate quality). To limit our analyses to individual ejaculate parameters in healthy men, we excluded data from studies that only reported composite scores (Leivers et al., 2014; Soler et al., 2014) and we excluded data from studies of clinical samples, leaving nine studies. Additionally, we reversed the sign (i.e. multiplied by -1) of each of the 2D:4D effects to account for the predicted negative relationship between ejaculate quality and 2D:4D that conflicts with the predicted positive relationship with factors related to attractiveness (in effect, we converted to 4D:2D). The mean weighted effect size of the relationship between all measured phenotypes (intelligence, attractiveness, symmetry, and 2D:4D) and percentage of motile sperm across eight studies was $\bar{Z}=0.045, S E=0.048, p>0.05, I^{2}=56 \%$. For sperm concentration, across six available studies (intelligence, attractiveness, symmetry, and 2D:4D), the mean weighted effect size was $\bar{Z}=0.011, S E=0.062, p>0.05, I^{2}=71 \%$. For sperm count, across five available studies (intelligence, symmetry, and 2D:4D), the mean weighted effect size was $\bar{Z}=0.125, S E=0.076, p$ $=0.0503, I^{2}=78 \%$. Only the relationship between the listed phenotypes and sperm count approached significance $(p=0.0503)$, suggesting that if a general fitness factor accounts for variation in ejaculate quality, it may do so via sperm number. Finally, we thought it prudent to report these analyses with the study of intelligence (Arden et al., 2009) removed, as its larger effects and sample may have moved the results closer to significance without resembling the weaker effects of the other, morphological phenotypes included in the analyses. Removing this study did indeed attenuate each of the mean effects (motility: $\bar{Z}=0.021, S E=0.052, p>0.05, I^{2}=46 \%$; concentration: $\bar{Z}=-0.028, S E=0.069, p>0.05, I^{2}=$ $63 \%$; count: $\bar{Z}=0.087, S E=0.069, p>0.05, I^{2}=62 \%$ ), even reversing the relationship between phenotype and sperm concentration.

The literature summarized here indicates that the percentage of motile sperm is not correlated with 2D:4D, although it appears to be correlated with factors related to mate choice (attractiveness and symmetry). However, when taken together, morphological phenotypes do not cumulatively correlate with 
any one of the three most commonly measured ejaculate parameters. From such a small number of studies ( $k=8$ in the largest set, $k=4$ in the smallest set), we can conclude little with confidence, except to suggest that future work will need to refine the set of human phenotypes and ejaculate parameters that are theoretically relevant. In the meantime, we encourage an examination of the measurement strategies employed in this area.

\section{Measuring Ejaculate Quality}

The quality of a man's ejaculate can be defined as the probability that it will produce viable offspring following copulation in a natural environment. However, in the study of human reproduction, ejaculate quality is often assessed in terms of sperm concentration, morphology, and motility, which are proxies for fertility (Bonde et al., 1998). "High quality ejaculates" differ from "high quality genes." High quality ejaculate refers to the semen parameters, and not to the genetic contents of sperm. That said, men's fertility is among the many traits encoded in "good genes" that women may have evolved to detect for their own benefit and for the benefit of their offspring. Various semen parameters comprise ejaculate quality, including ejaculate volume, total sperm number, sperm concentration, agglutination, semen viscosity (coagulation and liquefaction), semen $\mathrm{pH}$, sperm morphology, sperm vitality (cellular integrity), and the presence of cellular elements other than spermatozoa, such as genitourinary epithelial cells and leukocytes (World Health Organization, 2010; Johanisson et al., 2000). Principle components analyses consistently extract clusters of traits that covary (e.g., measures of motility, morphology, and concentration form a single principle component; Auger and Eustache, 2014; Leivers et al., 2014), suggesting an underlying ejaculate quality component.

The human semen parameters reported in the literature vary across studies, but typically include the percentage of motile sperm, sperm concentration, and sperm count. Although these three parameters influence the likelihood of fertilization, other parameters also influence the likelihood of fertilization (World Health Organization, 2010). Sperm number and concentration are less predictive of fertility than individual assessment of sperm kinematics (e.g., flagellar and head movement; Mortimer, 1997) and morphology (Bonde et al., 1998). Additionally, the differences in semen analysis techniques across time 
and place, and the difficulty in acquiring adequate numbers of ejaculates, complicates the crossexamination of the associations between phenotypic traits and ejaculate quality, even when the same semen parameters are assessed. For example, the study of 2D:4D ratio and semen quality conducted in China compared sperm motility in 196 infertile men and 72 healthy controls with computer-aided semen analysis, identifying the proportion of sperm in each ejaculate that displayed "class A or B" motility (moving faster than $5 \mu \mathrm{m} / \mathrm{s}$; Lu et al., 2012; World Health Organization, 2010). Another study of 2D:4D measured the percentage of motile sperm in 58 healthy American men, using a manual count of motile sperm in a Makler counting chamber under magnification (motility criteria were not specified; Manning et al., 1998). A third study of 2D:4D in 50 healthy Australian men generated motility classifications with a manual count of class A or B sperm at 10 different microscopic fields in a Neubauer counting chamber (Firman et al., 2003). It is difficult to know if the extant research correlating ejaculate quality with phenotypic traits can be defensibly integrated, given that the procedures, equipment, and samples are so varied (see Table 1).

The different techniques for semen assessment sometimes produce varying levels of agreement (Christensen et al., 2005; Mahmoud et al., 1997). In fact, retrospective reports of widespread declines in sperm concentration over the past 50 years might be accounted for by shifts in semen assessment technology and techniques (Pacey, 2013). Additionally, most studies that have investigated the correlation between human phenotypic traits and ejaculate quality have assessed masturbatory ejaculates, which are known to be lower in quality than copulatory ejaculates (Zavos and Goodpasture, 1989). Semen parameters vary under sociosexual circumstances such as the risk of sperm competition, but these effects are sometimes specific to copulatory samples (Baker and Bellis, 1993; Baker and Bellis, 1995). Studies using masturbatory samples do not fully account for ejaculate adjustments made in copulation (Baker and Bellis, 1993). We wish to explore how mate preferences evolved with respect to reproductively successful ejaculates, and because it is copulatory (and not masturbatory) ejaculate quality that influences reproductive success, assessing copulatory ejaculate quality is more appropriate in this line of research.

\section{Non-Human Studies}


In the non-human literature, the correlation between phenotypic traits and ejaculate quality varies by population, strain, species, and phenotypic trait, with attention limited to male secondary sexual characteristics (SSCs). Researchers have identified positive correlations between SSC development and ejaculate quality in several species. For example, the attractiveness of the courtship displays in wild Trinidadian guppies (Poecilia reticulata) varies from male to male by virtue of differences in swimming strength, coloration, and size, each of which is positively correlated with the number of sperm reserved in the reproductive tract and the number of sperm deposited in solicited copulations (controlling for sperm reserves; Matthews et al., 1997; Pilastro et al., 2002). Larger, more colorful male guppies, who are preferred as mating partners, also have larger, more abundant, and more motile sperm than their smaller rivals (Locatello et al., 2006; Skinner and Watt, 2006; see also, red deer, Malo et al., 2005; pied flycatchers, Calhim et al., 2009; houbara bustard, Chargé et al., 2013; fly, Hosken et al., 2008; dung beetle, Simmons and Kotiaho, 2002).

Other studies have found negative correlations between features of male SSCs and ejaculate quality. Female cod (Gadus morhua L.) assess mate quality through the sounds produced by males during courtship. Males with larger "drumming muscles" produce more attractive sounds, and drumming muscle size is negatively correlated with spermatocrit level (concentration of sperm in the ejaculate; Engen and Folstad, 1999; see also, red junglefowl, Parker et al., 2006; guppy, Evans, 2010). Researchers usually interpret such negative correlations as indicative of a developmental tradeoff between investment in male SSCs and investment in ejaculate quality (Mautz et al., 2013). In other cases, the relationship is interpreted as the result of attractive males either producing more frequent ejaculates and experiencing diminishing returns due to sperm depletion (Dewsbury, 1982; Preston et al., 2001), diverting sperm production resources to mate guarding and courtship behavior (Warneret al., 1995), down-regulating their ejaculate size in contexts of abundant non-competitive matings (Wedell et al., 2002), or all of the above. In several studies, there are no correlations found between features of male SSCs and ejaculate quality. For example, among Sedge warblers (Acrocephalus schoenobaenus), larger song repertoires are more attractive to females, but the size of the repertoire is not correlated with sperm numbers or with the 
percentage of morphologically normal sperm (Birkhead et al, 1997; see also, cricket: Klaus et al., 2011; pied flycatcher: Lifjeld et al., 2012; zebra finch: Birkhead and Fletcher, 1995). Evidence for the relevant associations is mixed in other studies. For example, in the domestic rooster (Gallus gallus domesticus), females are attracted to males that display larger and redder combs and sperm viability correlates positively with comb color but negatively with comb size (Navara et al., 2012; see also, fairy wren: Rowe et al., 2010).

In a meta-analysis of 38 studies of 21 non-human species, Mautz, Møller, and Jennions (2013) parsed 228 effect sizes for the correlations between behavioral and morphological male SSCs and various measures of ejaculate quality. The analyses yielded small but significant correlations between behavioral and morphological SSCs and sperm viability $(r=.07, p<.05)$, but these correlations failed to reach significance for sperm number, size, or swimming speed. The researchers conclude that although male phenotype accounted for less than $1 \%$ of the variance in sperm quality, small effect sizes can produce significant evolutionary trends (see Marczyk and Shackelford, 2010). They also warn that the varied methods of ejaculate extraction, the captive environment, and the operational definition of sperm quality are likely sources of error. As in the human literature, the method of collecting ejaculates varies by study. Of the studies included, some stimulate ejaculation manually, or with the use of mock female receptacles, other studies extract semen surgically or by mechanical pressure (post mortem), and still others extract the ejaculate from the female reproductive tract after copulation. Data on different sperm parameters from different species (e.g., sperm length in dung beetles and sperm number in guppies) are difficult to integrate because different parameters may be more or less relevant to fertility in different species. Moreover, semen parameters serve as proxies for fertility, and very few studies establish fertility by identifying paternity. Similar to human ejaculate quality, non-human ejaculate quality varies as a function of naturally occurring contexts, and only one of the studies referenced here (Calhim et al., 2009) assessed phenotype and fertility in a wild population.

\section{Conclusion}


The selection pressures that influence men's fertility are many and varied. A woman's preference for early fertilization, the clustering of fitness-enhancing traits in men of high genetic quality and developmental stability, and the selection of men who succeed in sperm competition are all predicted to produce correlations between male attractiveness and ejaculate quality. However, because there are nontrivial costs to producing high-quality ejaculates, men of high genetic quality more often benefit from prudently allocating investment in each ejaculate (e.g., Leivers et al., 2014): Although they may be most capable of producing viable ejaculates, these ejaculates are also in greatest demand. Moreover, men of higher phenotypic quality incur the costs of producing and maintaining those phenotypes, including the developmental costs of an elaborate morphology and the time and energy costs of dominance posturing and mate guarding. These costs weigh upon an attractive male's ability to manufacture high-quality ejaculates, driving down the correlation between phenotype and fertility. Thus, there may be a tug-of-war between these selection pressures, simultaneously pulling attractive males towards fertility and pushing them away from fertility. Depending on the species and the trait measured, the correlation between male phenotype and fertility can move in either direction.

Currently, the evidence for phenotypic traits as cues for male fertility in humans is mixed. Research has documented positive, negative, and no correlations between phenotypic traits and ejaculate quality. Unfortunately, the results across species do not align with any obvious life-history commonalities (degree of paternal investment, mating strategy, method of fertilization, etc.). The between-species differences in findings do not show patterns that help in identifying confounding factors. Therefore, we do not identify any a priori reason to expect one pattern or another across all human traits, and conclude that theory lags behind the data, creating a situation in which each finding (positive or negative) generates its own theoretical position of unknown generalizability. It is possible that the pattern of both positive and negative results indicates the lack of any consistent relationship between phenotype and fertility, but many of these studies produce effect sizes that are larger than this null hypothesis would predict, and most studies measure different traits or measure the same traits in different contexts. If evidence of adaptation can be extracted from this literature, it will require a more nuanced interpretation of the conditions under 
which a given phenotype, as assessed by a given female, corresponds with a given ejaculatory parameter as it relates to fertility. Each of these considerations must be made with explicit reference to human biology, ecology, and evolutionary history.

For researchers interested in developing and testing well-defined predictions on whether and how the relationship between men's phenotype and fertility may guide women's mate choice, we offer six methodological considerations. First, women's assessments of men's attractiveness should be carefully defined, with sensitivity to mating context and ovulatory cycle status. An ideal operational definition for male attractiveness will be open to objective validation, i.e., attractiveness should be established using both women's reports and direct measurement of men's traits so that we may refer more directly to phenotypes, rather than to the perception of phenotypes. We recommend that researchers secure measurements of male traits whose degree and context of attractiveness are established elsewhere (e.g., face shape, muscle mass, etc.) to identify traits that may be used as cues of ejaculate quality. When measurements are made, they should be made with image analysis software (e.g., ImageJ; Schneider, Rasband, and Eliceiri, 2012) for greater measurement accuracy, consistency, and efficiency.

Second, researchers might benefit from novel thinking with respect to the traits that may correlate with ejaculate quality. Female mate choices may be informed by a wide array of morphological, behavioral, and psychological traits, any of which may be heavily weighted for associations with ejaculate quality. We recommend that researchers begin by scanning for traits that correlate with ejaculate quality and explore how these traits relate to mate value (e.g., heritable psychopathologies, sexual preferences, personality measures, life histories, etc.). Third, investigators will benefit from the use of methods that rule out alternative explanations for the attractiveness of precisely-defined male traits. For example, if wrist width were correlated with ejaculate quality, but was otherwise linked with physiological costs, then female attraction to wrist width would constitute strong evidence for female adaptations to secure high quality ejaculates. Fourth, we recommend making the measurement of phenotypic traits and ejaculate quality more naturalistic and context-sensitive. Acquiring copulatory ejaculates from men in relationships, providing women with video stimuli or brief meetings rather than still images for ratings of 
attractiveness, and retrospective assessments of men's lifetime sexual behavior are methods that might help to approximate more natural mating contexts. Following Leivers et al. (2014), future researchers should account for the relative mate value of the men producing ejaculates and the women that stimulate their arousal. Additionally, the finding that women's long-term mate preferences differ from their shortterm mate preferences and that these preferences change across the ovulatory cycle also raises questions that have yet to be explored. Although most studies exclude women using hormonal contraceptives, few studies account for the ovulatory phase of the raters. This is most likely to complicate findings from studies using small numbers of female raters, as in Peters, Rhodes, and Simmons (2008; 12 women), who also did not exclude women using hormonal contraceptives. Fifth, due to ethnic, economic, and cultural differences in phenotype, attractiveness, and ejaculate quality, researchers must limit the scope of their findings to their study population. All the results we cite are drawn from developed nations, and most participants are college-educated. Research will need to assess non-industrialized, non-Western populations to explore whether the proposed relationships between male phenotype and fertility are universal. That said, unless there is theoretical reason to expect industrialized life to fundamentally alter female mating psychology, greater diversity may not be necessary in identifying female adaptations.

Finally, a proper assessment of the proposed relationships in humans requires developing consensus on the measurement of ejaculates and the traits that may correlate with ejaculate quality in men. Without consistent adherence to ejaculate measurement guidelines and consistent measurement of male traits, the literature will continue to be difficult to integrate. For example, in a meta-analysis of 94 studies investigating the correlations between FA and health outcomes in humans, Van Dongen and Gangestad (2011) identified hundreds of traits under study. Most studies aggregated bodily features or facial features, overlapping with or excluding measures from other studies, creating a situation in which the effect size of the correlation between FA and health outcomes was impossible to specify (but estimated to be between .08 and .67), despite a total sample of nearly 50,000 participants. In FA research, we recommend assessing traits that are influenced primarily by developmental instability, as opposed to lateralized behavior (handedness and footedness), and only those visible traits that ancestral women could 
have used to assess mate vale. Because evolutionary research on human ejaculate quality is relatively new, we recommend that future studies assess many trait indicators of ejaculate quality, as described by the World Health Organization (2010), using computer-aided semen analysis equipment. From here, it is essential that investigators are familiar with the evolving literature on how ejaculate characteristics interact to facilitate or decrease the likelihood of fertilization in humans, so that there can be agreement on which characteristics are relevant. In providing these recommendations we hope to encourage constructive conversation between researchers studying human mate choice, human reproductive biology, and related evolutionary forces, knowing that better methods and theoretical considerations will continue to emerge as these fields progress. 


\section{References}

Andersson M, Simmons LW. 2006. Sexual selection and mate choice. Trends in Ecology and Evolution 2:296-302.

Apicella CL, Feinberg DR, Marlowe FW. 2007. Voice pitch predicts reproductive success in male huntergatherers. Biology Letters 3:682-684.

Arden R, Gottfredson LS, Miller GF, Pierce A. 2009. Intelligence and semen quality are positively correlated. Intelligence 37:277-282.

Auger J, Eustache F. 2010. Second to fourth digit ratios male genital development and reproductive health: a clinical study among fertile men and testis cancer patients. International Journal of Andrology 34:e49-e58.

Baker RR. 1997. Copulation masturbation and infidelity: state-of-the-art. In: Atzwanger K, Grammer K, Schäfer K, Schmitt A, editors. New aspects of human ethology. New York: Plenum Press. p. $168-188$.

Baker RR, Bellis MA. 1989. Number of sperm in human ejaculates varies in accordance with sperm competition theory. Animal Behaviour 37:867-869.

Baker RR, Bellis MA. 1993a. Human sperm competition: ejaculate adjustment by males and the function of masturbation. Animal Behaviour 46:861-885.

Baker RR, Bellis MA. 1993b. Human sperm competition: ejaculate manipulation by females and a function for the female orgasm. Animal Behaviour 46:887-909.

Baker RR, Bellis MA. 1995. Human sperm competition: copulation masturbation and infidelity. London: Chapman Hall, Inc. 353 p.

Bang AK, Carlsen E, Holm M, Petersen JH, Skakkebæk NE, Jørgensen NJ. 2005. A study of finger lengths semen quality and sex hormones in 360 young men from the general Danish population. Human Reproduction 20:3109-3113.

Batty GD, Deary IJ, Gottfredson LS. 2007. Premorbid early life IQ and later mortality risk: systematic review. Annals of Epidemiology 17:278-288. 
Barcelo-Coblijn G, Kitajka K, Puskas LG, Hogyes E, Zvara A, Hackler L, Farkas T. 2003. Gene expression and molecular composition of phospholipids in rat brain in relation to dietary n-6 to n3 fatty acid ratio. Molecular and Cell Biology of Lipids 1632:72-79.

Bellis MA, Baker RR. 1990. Do females promote sperm competition? Data for humans. Animal Behaviour 40:997-999.

Birkhead TR, Buchanan KL, Devoogd TJ, Pellatt EJ, Székely T, Catchpole CK. 1997. Song sperm quality and testes asymmetry in the sedge warbler. Animal Behaviour 53:965-971.

Birkhead TR, Fletcher F. 1995. Male phenotype and ejaculate quality in the zebra finch (Taeniopygia guttata). Proceedings of the Royal Society B 262:329-334.

Birkhead TR, Møller A, Sutherland W. 1993. Why do females make it so difficult for males to fertilize their eggs? Journal of Theoretical Biology 161:51-60.

Boivin J, Bunting L, Collins JA, Nygren KG. 2007. International estimates of infertility prevalence and treatment-seeking: potential need and demand for infertility medical care. Human Reproduction 22:1506-1512.

Bonde J, Ernst E, Jensen T. 1998. Relation between semen quality and fertility: a population-based study of 430 first-pregnancy planners. The Lancet 54:247-249.

Calhim S, Lampe HM, Slagsvold T, Birkhead TR. 2009. Selection on sperm morphology under relaxed sperm competition in a wild passerine bird. Biology Letters 5:58-61.

Chargé R, Saint Jalme M, Lacroix F, Cadet A, Sorci G. 2010. Male health status signaled by courtship display reveals ejaculate quality and hatching success in a lekking species. The Journal of Animal Ecology 79:843-850.

Christensen P, Stryhn H, Hansen C. 2005. Discrepancies in the determination of sperm concentration using Bürker-Türk, Thoma, and Makler counting chambers. Theriogenology 63:992-1003.

Collins SA. 2000. Men's voices and women's choices. Animal Behaviour 60:773-780. 
Cosmides L, Tooby J. 2002. Unraveling the enigma of human intelligence: evolutionary psychology and the multimodular mind. In: Sternberg RJ, Kaufman JC, editors. The evolution of intelligence. Mahwah NJ: Erlbaum. p 145-198.

Dewsbury D. 1982. Ejaculate cost and male choice. American Naturalist 119:601-610.

Donnelly ET, Lewis SEM, McNally JA, Thompson W. 1998. In vitro fertilization and pregnancy rates: The influence of sperm motility and morphology on IVF outcome. Fertility and Sterility 70:305314.

Engen F, Folstad I. 1999. Cod courtship song: a song at the expense of dance? Canadian Journal of Zoology 77:542-550.

Evans JP. 2010. Quantitative genetic evidence that males trade attractiveness for ejaculate quality in guppies. Proceedings of the Royal Society B 277:3195-3201.

Evans S, Neave N, Wakelin D. 2006. Relationship between vocal characteristics and body size and shape in human males: an evolutionary explanation for a deep male voice. Biological Psychiatry 72:160-163.

Feinberg DR, Jones BC, Little AC, Burt DM, Perrett DI. 2005. Manipulations of fundamental and formant frequencies influence the attractiveness of human male voices. Animal Behaviour 69:561-568.

Feingold A. 1992. Gender differences in mate selection preferences: a test of the parental investment model. Psychological Bulletin 112:125-139.

Ferdenzi C, Lemaitre J, Leongomez JD, Roberts C. 2011. Digit ratio 2D:4D predicts facial but not voice or body odour attractiveness in men. Proceedings of the Royal Society B 278:3551-3557.

Ferlin A, Raicu F, Gatta V, Zuccarello D, Palka G, Foresta, C. 2007. Male infertility: Role of genetic background. Reproductive Biomedicine Online 14:734-745.

Firman RC, Simmons LW, Cummins JM, Matson PL. 2003. Are body fluctuating asymmetry and the ratio of $2^{\text {nd }}$ to $4^{\text {th }}$ digit length reliable predictors of semen quality? Human Reproduction 18:808812. 
Furlow B, Armijo-Prewitt T, Gangestad S, Thornhill R. 1997. Fluctuating asymmetry and psychometric intelligence. Proceedings of the Royal Society B 264:823-829.

Gallup G, Burch R, Mitchell T. 2006. Semen displacement as a sperm competition strategy. Human Nature 17:253-264.

Gangestad SW, Garver-Apgar CE, Simpson J, Cousins AJ. 2007. Changes in women's mate preferences across the ovulatory cycle. Journal of Personality and Social Psychology 92:151-163.

Gangestad SW, Simpson J. 2000. The evolution of human mating: trade-offs and strategic pluralism. The Behavioral and Brain Sciences 23:573-587.

Gangestad SW, Thornhill R, Garver-Apgar CE. 2005. Women's sexual interests across the ovulatory cycle depend on primary partner developmental instability. Proceedings of the Royal Society B: Biological Sciences 272:2023-2027.

Gangestad SW, Thornhill R, Yeo RA. 1994. Facial attractiveness developmental stability and fluctuating asymmetry. Ethology and Sociobiology 15:73-85.

Gildersleeve K, Haselton MG, Fales MR. 2014. Do women's mate preferences change across the ovulatory cycle? A meta-analytic review. Psychological Bulletin 140:1205-1259.

Goetz AT, Shackelford TK, Weekes-Shackelford VA, Euler HA, Hoier S, Schmitt DP, LaMunyon CW. 2005. Mate retention semen displacement and human sperm competition: a preliminary investigation of tactics to prevent and correct female infidelity. Personality and Individual Differences 38:749-763.

Grammer K, Thornhill R. 1994. Human (Homo sapiens) facial attractiveness and sexual selection: the role of symmetry and averageness. Journal of Comparative Psychology 108:233-242.

Haselton MG, Miller GF. 2006. Women's fertility across the cycle increases the short-term attractiveness of creative intelligence. Human Nature 17:50-73.

Hedges LV, Olkin I. 1985. Statistical methods for meta-analysis. Orlando, FL: Academic Press.

Herault Y, Fradeau N, Zakany J, Duboule D. 1997. Ulnaless (Ul) a regulatory mutation inducing both loss-of-function and gain-of-function of posterior HoxD genes. Development 124:3493-3500. 
Higgins JPT, Thompson SG. 2002. Quantifying heterogeneity in a meta-analysis. Statistics in Medicine 21:1539-1558.

Hirano Y, Shibahara H, Obara H, Suzuki T, Takamizawa S, Yamaguchi C, ... Sato I. 2001. Relationships between sperm motility characteristics assessed by the computer-aided sperm analysis (CASA) and fertilization rates in vitro. Journal of Assisted Reproduction and Genetics 18:213-218.

Hodges-Simeon CR, Gaulin SJC, Puts D. 2011. Voice correlates of mating success in men: examining “contests" versus "mate choice" modes of sexual selection. Archives of Sexual Behavior 40:551557.

Hosken DJ, Taylor ML, Hoyle K, Higgins S, Wedell N. 2008. Attractive males have greater success in sperm competition. Current Biology 18:553-554.

Houle D. 2000. Is there a g factor for fitness? In: Bock G, Goodle J, Webb K, editors. The nature of intelligence. New York: Wiley. p 149-170.

Hughes SM, Dispenza F, Gallup GG. 2004. Ratings of voice attractiveness predict sexual behavior and body configuration. Evolution and Human Behavior 25:295-304.

Jenkins JS. 1998. The voice of the Castrato. Lancet 351:1877-1880.

Johanisson E, Campana A, Luthi R, De Agostino A. 2000. Evaluation of "round cells" in semen analysis: a comparative study. Human Reproduction Update 6:404-412.

Johnstone RA, Keller L. 2000. How males can gain by harming their mates: sexual conflict seminal toxins and the cost of mating. The American Naturalist 156:368-377.

Klaus SP, Fitzsimmons LP, Pitcher TE, Bertram SM. 2011. Song and sperm in crickets: a trade-off between pre- and post-copulatory traits or phenotype-linked fertility? Ethology 117:154-162.

Kościński K. 2011. Determinants of hand attractiveness-A study involving digitally manipulated stimuli. Perception 40:682-694.

Kościński K. 2012. Hand attractiveness-Its determinants and associations with facial attractiveness. Behavioral Ecology 23:334-342. 
Lefevre CE, Lewis GJ, Perrett DI, Penke L. 2013. Telling facial metrics: facial width is associated with testosterone levels in men. Evolution and Human Behavior 34:273-279.

Leivers S, Rhodes G, Simmons LW. 2014. Context-dependent relationship between a composite measure of men's mate value and ejaculate quality. Behavioral Ecology 25:1115-1122.

Lenzi A, Gandidi L, Maresca V, Rago R, Sgrò P, Dondero F, Picardo M. 2000. Fatty acid composition of spermatozoa and immature germ cell. Molecular Human Reproduction 6:226-231.

Li NP, Bailey JM, Kenrick DT, Lisenmeier JAW. 2002. The necessities and luxuries of mate preferences: testing the tradeoffs. Journal of Personality and Social Psychology 82:947-955.

Li NP, Kenrick DT. 2006. Sex similarities and differences in preferences for short-term mates: what whether and why. Journal of Personality and Social Psychology 90:468-489.

Lifjeld JT, Laskemoen T, Kleven O, Pedersen TM, Lampe HM, Rudolfsen G, ... Slagsvold T. 2012. No evidence for pre-copulatory sexual selection on sperm length in a passerine bird. PloS One $7: \mathrm{e} 32611$.

Little AC, Burt DM, Pentok-Voak IS, Perrett DI. 2001. Self-perceived attractiveness influences human female preferences for sexual dimorphism and symmetry in male faces. Proceedings of the Royal Society B 268:39-44.

Little AC, Jones BC, Penton-Voak IS, Burt DM, Perrett DI. 2002. Partnership status and the temporal context of relationships influence human female preferences for sexual dimorphism in male face shape. Proceedings of the Royal Society B 269:1095-1100.

Locatello L, Rasotto MB, Evans JP, Pilastro A. 2006. Colourful male guppies produce faster and more viable sperm. Journal of Evolutionary Biology 19:1595-1602.

Lu H, Huo Z, Liu Y, Shi Z, Zhao J. 2012. Correlations between digit ratio and infertility in Chinese men. Early Human Development 88:865-869.

Lutchmaya S, Baron-Cohen S, Raggatt P, Knickmeyer R, Manning JT. 2004. $2^{\text {nd }}$ to $4^{\text {th }}$ digit ratios, fetal testosterone, and estradiol. Early Human Development 77:23-28. 
Luxen MF, Buunk BP. 2006. Human intelligence fluctuating asymmetry and the peacock's tail: general intelligence $\mathrm{g}$ as an honest signal of fitness. Personality and Individual Differences 41:897-902.

Lynn R. 1990. Testosterone and gonadotropin levels and r/K reproductive strategies. Psychological Reports 67:1203-1206.

Mahmoud AM, Depoorter B, Piens N, Comhaire FH. 1997. The performance of 10 different methods for the estimation of sperm concentration. Fertility and Sterility 68:340-345.

Malo AF, Roldan ERS, Garde J, Soler AJ, Gomendio M. 2005. Antlers honestly advertise sperm production and quality. Proceedings of the Royal Society B 272:149-157.

Manning JT. 2002. Digit ratio: a pointer to fertility behavior and health. New Brunswick NJ: Rutgers University Press, Inc. 173 p.

Manning JT, Scutt D, Lewis-Jones DI. 1998a. Developmental stability ejaculate size and sperm quality in men. Evolution and Human Behavior 19:273-282.

Manning JT, Scutt D, Wilson J, Lewis-Jones DI. 1998b. The ratio of 2nd to 4th digit length: a predictor of sperm numbers and concentration of testosterone luteinizing hormone and oestrogen. Human Reproduction 13:3000-3004.

Manning JT, Taylor RP. 2001. Second to fourth digit ratio and male ability in sport: Implications for sexual selection in humans. Evolution and Human Behavior 22:61-69.

Marczyk JB, Shackelford TK. 2010. A biased, incomplete perspective on the evolution of human mating systems: A review of Alan F. Dixson, Sexual Selection and the Origins of Human Mating Systems. Evolutionary Psychology 8:31-36.

Matthews IM, Evans JP, Magurran AE. 1997. Male display rate reveals ejaculate characteristics in the Trinidadian guppy. Proceedings of the Royal Society B 264:695-700.

Mautz BS, Møller AP, Jennions MD. 2013. Do male secondary sexual characters signal ejaculate quality? A meta-analysis. Biological Reviews of the Cambridge Philosophical Society 88:669-682.

Mays HL, Hill GE. 2004. Choosing mates: good genes versus genes that are a good fit. Trends in Ecology and Evolution 19:554-559. 
Mendiola J, Torres-Cantero AM, Moreno-Grau JM, Ten J, Roca M, Moreno-Grau S, Bernabeu R. 2009. Food intake and its relationship with semen quality: a case-control study. Fertility and Sterility $91: 812-818$.

Mortimer ST. 2006. A critical review of the physiological importance and analysis of sperm movement in mammals. Human Reproduction Update 3:403-439.

Mortlock DP, Innis JW. 1997. Mutation of HoxA 13 in hand-foot-genital syndrome. Nature Genetics 15:179-180.

Mosher WD. 1985. Reproductive impairments in the United States 1965-1982. Demography 22:415-430.

Moyer D, Rimdusit S, Mishell D. 1970. Sperm distribution and degradation in the human female reproductive tract. Obstetrics and Gynecology 35:831-840.

Navara KJ, Anderson EM, Edwards ML. 2012. Comb size and color relate to sperm quality: a test of the phenotype-linked fertility hypothesis. Behavioral Ecology 23:1036-1041.

Nummi P, Pellikka J. 2012. Do female sex fantasies reflect adaptations for sperm competition? Annales Zoologici Fennici 49:93-102.

O’Flynn O'Brien KL, Varghese AC, Agarwal A. 2010. The genetic causes of male factor infertility: A review. Fertility and Sterility, 93:1-12.

Pacey A. 2013. Are sperm counts declining? Or did we just change our spectacles? Asian Journal of Andrology 15:187-190.

Parapanov RN, Nusslé S, Crausaz M, Senn A, Hausser J, Vogel P. 2009. Testis size, sperm characteristics, and testosterone concentrations in four species of shrews (Mammalia, Soricidae). Animal Reproduction Science 114:269-278.

Parker G, Lessells C, Simmons L. 2013. Sperm competition games: a general model for precopulatory male-male competition. Evolution 67:95-109.

Parker TH, Thompson D, Ligon JD, Schneider B, Byrn F. 2006. Does red junglefowl comb size predict sperm swimming speed and motility? Ethology, Ecology, and Evolution 276:53-60. 
Peichel CL, Prabhakaran B, Vogt TF. 1997. The mouse Ulnaless mutation deregulates posterior HoxD gene expression and alters appendicular patterning. Development 124:3481-3492.

Penton-Voak I, Perrett D. 2000. Female preference for male faces changes cyclically: further evidence. Evolution and Human Behavior 21:39-48.

Peters M, Rhodes G, Simmons LW. 2008. Does attractiveness in men provide clues to semen quality? Journal of Evolutionary Biology 21:572-579.

Peters M, Rhodes G, Simmons LW. 2007. Contributions of the face and body to overall attractiveness. Animal Behaviour 73:937-942.

Pham MN, Shackelford TK. 2013. The relationship between objective sperm competition risk and men's copulatory interest is moderated by partner's time spent with other men. Human Nature 24:476485.

Pham MN, Shackelford TK. 2014. Human sperm competition: a comparative evolutionary analysis. Animal Behavior and Cognition 1:410-422.

Pham MN, Shackelford TK, Holden CJ, Zeigler-Hill V, Hummel A, Memering S. 2014. Partner attractiveness moderates the relationship between number of sexual rivals and in-pair copulation frequency in humans Homo sapiens. Journal of Comparative Psychology 128:328-331.

Pierce A, Miller GF, Arden R, Gottfredon S. 2009. Why is intelligence correlated with semen quality? Communicative and Integrative Biology 2:385-387.

Pilastro A, Evans JP, Sartorelli S, Bisazza A. 2002. Male phenotype predicts insemination success in guppies. Proceedings of the Royal Society B 269:1325-1330.

Pillsworth EG, Haselton MG. 2006. Male sexual attractiveness predicts differential ovulatory shifts in female extra-pair attraction and male mate retention. Evolution and Human Behavior 27:247-258.

Pitcher TE, Doucet SM, Beausoleil JJ, Hanley D. 2009. Secondary sexual characters and sperm traits in coho salmon (Oncorhynchus kisutch). Journal of Fish Biology 74:1450-1461.

Pizzari T, Birkhead TR. 2002. The sexually-selected sperm hypothesis: sex-biased inheritance and sexual antagonism. Biological Reviews of the Cambridge Philosophical Society 77:183-209. 
Povey AC, Clyma J, McNamee R, Moore HD, Baillie H, Pacey AA, Cherry NM. 2012. Modifiable and non-modifiable risk factors for poor semen quality: a case-referent study. Human Reproduction 27:2799-2806.

Preston BT, Stevenson IR, Pemberton JM, Wilson K. 2001. Dominant rams lose out by sperm depletion. Nature 409:681-682.

Price T, Schluter D, Heckman NE. 1993. Sexual selection when the female directly benefits. Biological Journal of the Linnean Society 48:187-211.

Prokosch MD, Coss RG, Scheib JE, Blozis SA. 2009. Intelligence and mate choice: intelligent men are always appealing. Evolution and Human Behavior 30:11-20.

Prokosch MD, Yeo RA, Miller GF. 2005. Intelligence tests with higher g-loadings shows higher correlations with body symmetry: evidence for a general fitness factor mediated by developmental stability. Intelligence 33:203-213.

Puts DA, Apicella CL, Cárdenas RA. 2012. Masculine voices signal men's threat potential in forager and industrial societies. Proceedings of the Royal Society 279:601-609.

Ravel J, Gajer P, Abdo Z, Schneider GM, Koenig SSK, McCulle SL, ... Forney LJ. 2011. Vaginal microbiome of reproductive-age women. Proceedings of the National Academy of Sciences 108:4680-4687.

Roney JR, Simmons ZL. 2008. Women's estradiol predicts preference for facial cues of men's testosterone. Hormones and Behavior 53:14-19.

Rowe M, Swaddle JP, Pruett-Jones S, Webster MS. 2010. Plumage coloration ejaculate quality and reproductive phenotype in the red-backed fairy-wren. Animal Behaviour 79:1239-1246.

Sadalla EK, Kenrick DT, Vershure B. 1987. Dominance and heterosexual attraction. Journal of Personality and Social Psychology 52:730-738.

Saino N, Romano M, Innocenti P. 2006. Length of index and ring fingers differentially influence sexual attractiveness of men's and women's hands. Behavioral Ecology and Sociobiology, 60:447-454. 
Scheib JE, Gangestad SW, Thornhill R. 1999. Facial attractiveness, symmetry and cues of good genes. Proceedings of the Royal Society B 266:1913-1917.

Schneider CA, Rasband WS, Eliceiri KW. 2012. NIH Image to ImageJ: 25 years of image analysis. Nature Methods 9:671-675.

Seo H, Kim KY, Rho J. 2010. Is the index finger and ring finger ratio 2D:4D reliable predictor of semen quality? Korean Journal of Urology 51:208-211.

Shackelford TK, Goetz A. 2006. Comparative evolutionary psychology of sperm competition. Journal of Comparative Psychology 120:139-146.

Shackelford TK, Goetz AT, McKibbin WF, Starratt VG. 2007. Absence makes the adaptations grow fonder: Proportion of time apart from partner, male sexual psychology, and sperm competition in humans (Homo sapiens). Journal of Comparative Psychology 121:214-220.

Shackelford TK, LeBlanc GJ, Weekes-Shackelford VA, Bleske-Rechek AL, Euler HA, Hoier S. 2002. Psychological adaptation to human sperm competition. Evolution and Human Behavior 23:123138.

Shackelford TK, Pound N, Goetz A. 2005. Psychological and physiological adaptations to sperm competition in humans. Review of General Psychology 9:228-248.

Sheldon BC. 1994. Male phenotype fertility and the pursuit of extra-pair copulations by female birds. Proceedings of the Royal Society B 257:25-30.

Simmons LW, Firman RC, Rhodes G, Peters M. 2004. Human sperm competition: testis size sperm production and rates of extrapair copulations. Animal Behaviour 68:297-302.

Simmons LW, Kotiaho J. 2002. Evolution of ejaculates: patterns of phenotypic and genotypic variation and condition dependence in sperm competition traits. Evolution 56:1622-1631.

Simmons LW, Peters MP, Rhodes G. 2011. Low pitched voices are perceived as masculine and attractive but do they predict semen quality in men? PLoS One 6:e29271. 
Simmons LW, Tinghitella RM, Zuk M. 2010. Quantitative genetic variation in courtship song and its covariation with immune function and sperm quality in the field cricket (Teleogryllus oceanicus). Behavioral Ecology 21:1330-1336.

Sjögren B, Gottlieb C. 2001. Testosterone for male contraception during one year: Attitudes, well-being and quality of sex life. Contraception 64:59-65.

Skinner AMJ, Watt PJ. 2006. Phenotypic correlates of spermatozoon quality in the guppy (Poecilia reticulate). Behavioral Ecology 18:47-52.

Soler C, Kekäläinen J, Núñez M, Sancho M, Núñez J, Yaber I, Gutiérrez R. 2012. Male facial anthropometry and attractiveness. Perception 41:1234-1245.

Soler C, Kekäläinen J, Núñez M, Sancho M, Alvarez JG Núñez J, ... Gutiérrez R. 2014. Male facial attractiveness and masculinity may provide sex- and culture-independent cues to semen quality. Journal of Evolutionary Biology 27:1930-1938.

Soler C, Núñez M, Gutiérrez R, Núñez J, Medina P, Sancho M, ... Núñez A. 2003. Facial attractiveness in men provides clues to semen quality. Evolution and Human Behavior 24:199-207.

Suarez SS, Pacey AA. 2006. Sperm transport in the female reproductive tract. Human Reproduction Update 12:23-37.

Tamara Montrose V, Edwin Harris W, Moore AJ, Moore PJ. 2008. Sperm competition within a dominance hierarchy: investment in social status vs. investment in ejaculates. Journal of Evolutionary Biology 21:1290-1296.

Thornhill R, Gangestad SW. 1994. Human fluctuating asymmetry and sexual behavior. Psychological Science 5:297-302.

Thornhill R, Gangestad SW. 1999a. Facial attractiveness. Trends in Cognitive Sciences 3:452-460.

Thornhill R, Gangestad SW. 1999b. Facial attractiveness symmetry and cues of good genes. Proceedings of the Royal Society B 266:1913-1917.

Tielemans E. 2002. Sources of bias in studies among infertility clients. American Journal of Epidemiology 156:86-92. 
Tielemans E, Burdorf A, te Velde ER, Weber RFA, van Kooij RJ, Veulemans H, Heederik DJJ. 1999. Occupationally related exposures and reduced semen quality: a case-control study. Fertility and Sterility 71:690-696.

Van Dongen S, Gangestad SW. 2011. Human fluctuating asymmetry in relation to health and quality: a meta-analysis. Evolution and Human Behavior 32:380-398.

von Rueden C, Gurven M, Kaplan H. 2011. Why do men seek status? Fitness payoffs to dominance and prestige. Proceedings of the Royal Society B 278:2223-2232.

Voracek M, Dressler SG, Manning, JT. 2007. Evidence for assortative mating on digit ratio (2D: 4D), a biomarker for prenatal androgen exposure. Journal of Biosocial Science 39:599-612.

Walker WH. 2009. Molecular mechanisms of testosterone action in spermatogenesis. Steroids 74:602607.

Warner RR, Shapiro DY, Marcanato A, Petersen CW. 1995. Sexual conflict: males with highest mating success convey the lowest fertilization benefits to females. Proceedings of the Royal Society B 262:135-139.

Wedell N, Gage MJG, Parker GA. 2002. Sperm competition male prudence and sperm-limited females. Trends in Ecology and Evolution 17:313-320.

Wira CR, Fahey JV, Ghosh M, Patel MV, Hickey DK, Ochiel DO. 2012. Review article: sex hormone regulation of innate immunity in the female reproductive tract: the role of epithelial cells in balancing reproductive potential with protection against sexually transmitted pathogens. American Journal of Reproductive Immunology 63:544-565.

World Health Organization. 1987. Towards more objectivity in diagnosis and management of male infertility. International Journal of Andrology 7:1-53.

World Health Organization. 2010. WHO laboratory manual for the examination and processing of human semen. Cambridge MA: Cambridge University Press, Inc. 287 p.

Zavos PM, Goodpasture JC. 1989. Clinical improvements of specific seminal deficiencies via intercourse with a seminal collection device versus masturbation. Fertility and Sterility 51:190-193. 
Zheng Z, Cohn MJ. 2011. Developmental basis of sexually dimorphic digit ratios. Proceedings of the National Academy 108:16289-16294. 
Table 1. Published research on the relationship between human male phenotypic traits and ejaculate quality

\begin{tabular}{|c|c|c|c|c|c|}
\hline Author(s) & Participants and Equipment & Phenotype & Semen Parameter(s) & Results & Notes \\
\hline $\begin{array}{l}\text { Arden, Gottfredson, } \\
\text { Miller, and Pierce } \\
\text { (2009) }\end{array}$ & $\begin{array}{l}425 \text { US veterans aged } 37.6(2.6) \\
\text { years } \\
\text { Cellsoft CASA }\end{array}$ & $\begin{array}{l}\text { Intelligence: Composite score } \\
\text { derived from } 5 \text { different spatial, } \\
\text { quantitative, and verbal scores }\end{array}$ & $\begin{array}{l}\text { Sperm concentration } \\
\text { Sperm count } \\
\text { Percentage of motile sperm }\end{array}$ & $\begin{array}{l}r=0.15^{* *} \\
r=0.19 * * \\
r=0.14 * *\end{array}$ & \\
\hline $\begin{array}{l}\text { Auger and Eustache } \\
\text { (2010) }\end{array}$ & $\begin{array}{l}193 \text { French men, } 122 \text { with } \\
\text { pregnant partners, } 71 \text { infertile } \\
\text { testicular cancer patients, aged } \\
32.8 \text { (4.6) and } 30.4 \text { (5.1) years, } \\
\text { respectively } \\
\text { Unspecified analysis equipment }\end{array}$ & $\begin{array}{l}\text { 2D:4D ratio: Right hand, fingers } \\
\text { measured with caliper while bent } \\
\text { over the edge of a table }\end{array}$ & $\begin{array}{l}\text { Sperm concentration } \\
\text { Sperm count } \\
\text { Percentage of living sperm } \\
\text { Percentage of motile sperm } \\
\text { Percentage of morphologically } \\
\text { normal sperm }\end{array}$ & $\begin{array}{l}r=-0.15 \\
r=-0.18^{*} \\
r=-0.02 \\
r=0.03 \\
r=-0.09\end{array}$ & $\begin{array}{l}\text { Data from men with } \\
\text { pregnant partners shown } \\
\text { Among cancer patients, no } \\
\text { relationships between } \\
\text { 2D:4D and semen } \\
\text { parameters approached } \\
\text { significance }\end{array}$ \\
\hline Baker (1997) & $\begin{array}{l}34 \text { British students aged } 19-22 \\
\text { years } \\
\text { Neubauer haemocytometer }\end{array}$ & $\begin{array}{l}\text { FA: Composite score derived from } \\
\text { bilateral caliper measurements of } \\
\text { index fingers, ears, wrists, and } \\
\text { ankles }\end{array}$ & Sperm count & $F=5.599 *$ & $\begin{array}{l}\text { Bilateral symmetry was } \\
\text { strongly correlated with } \\
\text { rated attractiveness }\end{array}$ \\
\hline $\begin{array}{l}\text { Bang, Charlsen, } \\
\text { Holm, Petersen, } \\
\text { Skakkbaek, and } \\
\text { Jorgensen (2005) }\end{array}$ & $\begin{array}{l}360 \text { Danish men aged } 19.5(1.1) \\
\text { years } \\
\text { Bürker-Türk haemocytometer }\end{array}$ & $\begin{array}{l}\text { 2D:4D ratio: Right hand traced on } \\
\text { paper and measured }\end{array}$ & $\begin{array}{l}\text { Sperm concentration } \\
\text { Sperm count } \\
\text { Percentage of motile sperm } \\
\text { Ejaculate volume }\end{array}$ & $\begin{array}{l}r=-0.004 \\
r=-0.004 \\
r=-0.007 \\
r=0.053\end{array}$ & $\begin{array}{l}\text { For men with } 2 \mathrm{D}: 4 \mathrm{D} \leq 1 \text {, } \\
\text { positive correlation } \\
\text { between } 2 \mathrm{D}: 4 \mathrm{D} \text { and sperm } \\
\text { count, } B=8.1^{*}\end{array}$ \\
\hline
\end{tabular}




\begin{tabular}{|c|c|c|c|c|c|}
\hline $\begin{array}{l}\text { Firman, Simmons, } \\
\text { Cummins, and } \\
\text { Matson (2003) }\end{array}$ & $\begin{array}{l}50 \text { Australian students, } 18-35 \\
\text { years } \\
\text { Neubauer haemocytometer }\end{array}$ & $\begin{array}{l}\text { FA: Composite score derived from } \\
\text { bilateral caliper measurements of } \\
\text { ears, wrists, elbows, ankles, foots, } \\
\text { and digits }\end{array}$ & $\begin{array}{l}\text { Sperm count } \\
\text { Percentage of motile sperm } \\
\text { Sperm head length } \\
\text { Sperm tail length }\end{array}$ & $\begin{array}{l}t=2.28^{*} \\
t=2.03^{*} \\
t=2.18^{*} \\
t=0.71\end{array}$ & $\begin{array}{l}\text { Univariate tests shown } \\
\text { Only body FA was } \\
\text { positively associated with } \\
\text { semen parameters }\end{array}$ \\
\hline $\begin{array}{l}\text { Leivers, Rhodes, } \\
\text { and Simmons } \\
\text { (2014) }\end{array}$ & $\begin{array}{l}81 \text { Australian students, } 22.2 \\
\text { (4.5) years } \\
\text { Hamilton-Thorne CASA }\end{array}$ & $\begin{array}{l}\text { Mate value: Composite score } \\
\text { derived from men's self-rated mate } \\
\text { value and women's ratings of those } \\
\text { men's attractiveness and } \\
\text { dominance }\end{array}$ & $\begin{array}{l}\text { Semen quality: Composite score } \\
\text { derived from sperm } \\
\text { concentration, motile sperm } \\
\text { percentage, and several } \\
\text { measures of sperm velocity }\end{array}$ & $\begin{array}{l}\text { Attractive } \\
\text { stimuli: } \\
\beta=0.377^{*} \\
\text { Unattractive } \\
\text { stimuli: } \\
\beta=-0.127\end{array}$ & $\begin{array}{l}\text { Men masturbated to } \\
\text { stimuli rated for high or } \\
\text { low attractiveness } \\
\text { Women rated short-term } \\
\text { sexual attractiveness }\end{array}$ \\
\hline $\begin{array}{l}\text { Lu, Huo, Liu, Shi, } \\
\text { and Zhao, (2012) }\end{array}$ & $\begin{array}{l}\text { 268 Chinese men, } 72 \text { controls } \\
\text { aged } 29.8 \text { (5.6) years and } 196 \\
\text { diagnosed infertile aged } 31.5 \\
\text { (6.7) years } \\
\text { WLJY-9000 CASA }\end{array}$ & $\begin{array}{l}\text { 2D:4D ratio: Left hand } \\
\text { photocopied and images measured }\end{array}$ & Percentage of motile sperm & $\begin{array}{l}\text { Among } \\
\text { controls: } \\
r=0.051 \\
\text { Among } \\
\text { infertile: } \\
r=.341^{* *}\end{array}$ & $\begin{array}{l}\text { Infertile men had } \\
\text { significantly larger 2D:4D } \\
\text { than controls, } t=3.43^{* *} \\
\text { 2D:4D on the left hand } \\
\text { showed the strongest } \\
\text { effect of all finger pairs }\end{array}$ \\
\hline $\begin{array}{l}\text { Manning, Scutt, } \\
\text { and Lewis-Jones } \\
\text { (1998a) }\end{array}$ & $\begin{array}{l}61 \text { British men attending a } \\
\text { fertility clinic aged } 33.5(6.2) \\
\text { years } \\
\text { Makler haemocytometer }\end{array}$ & $\begin{array}{l}\text { FA: Composite score derived from } \\
\text { differences between caliper } \\
\text { measurements of digit lengths on } \\
\text { right and left hands, measured } \\
\text { from crease to tip of finger }\end{array}$ & $\begin{array}{l}\text { Sperm count } \\
\text { Sperm speed } \\
\text { Sperm migration test }\end{array}$ & $\begin{array}{l}B=-17.04^{*} \\
B=-17.95^{*} \\
B=-10.05^{*}\end{array}$ & $\begin{array}{l}\text { Relationships } \\
\text { nonsignificant when } \\
\text { azoospermic men } \\
\text { removed }\end{array}$ \\
\hline
\end{tabular}




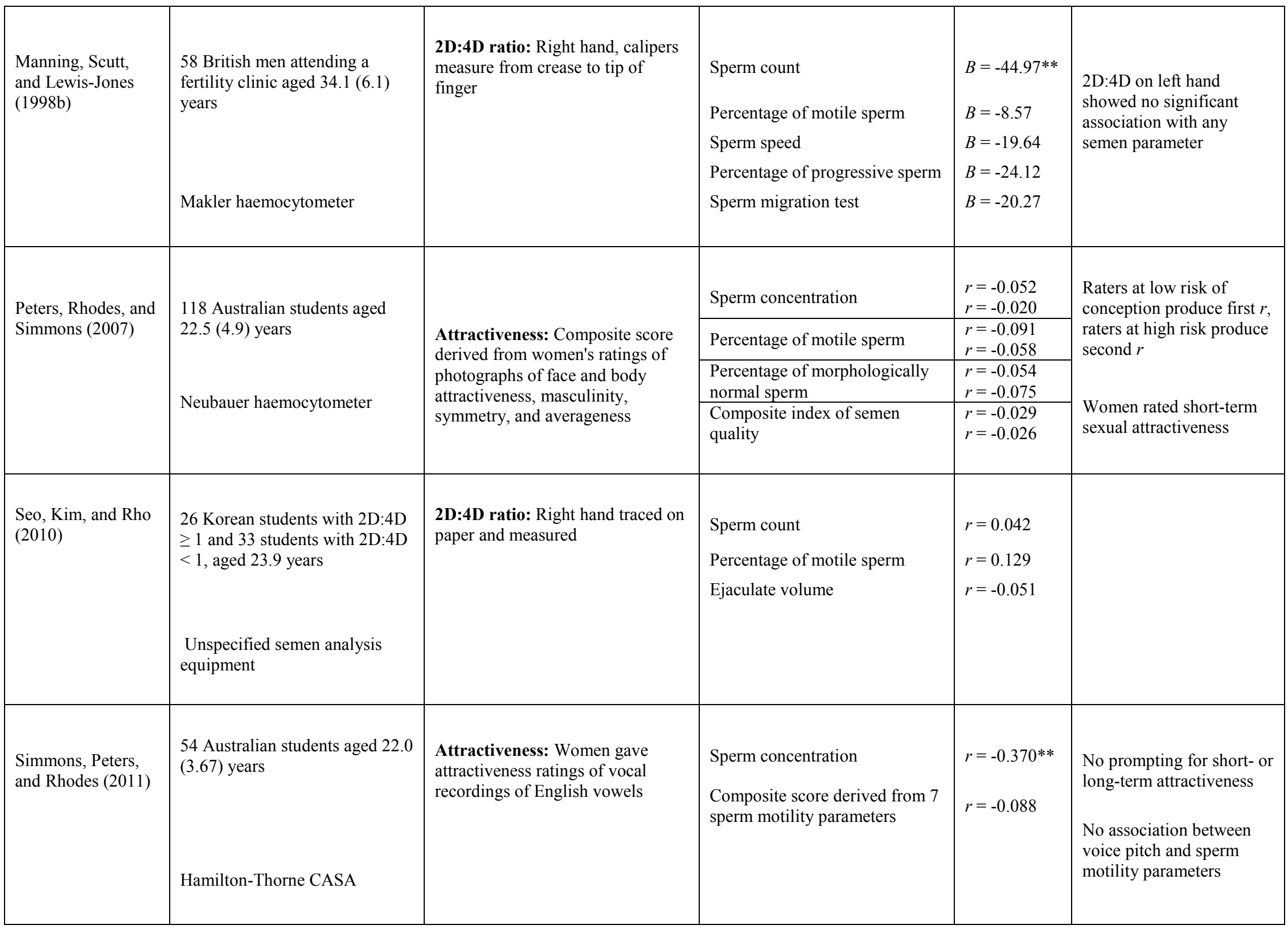




\begin{tabular}{|l|l|l|l|l|l|}
\hline Soler et al. (2014) & $\begin{array}{l}\text { 50 Spanish students aged 22.7 } \\
\text { (3.0) years }\end{array}$ & $\begin{array}{l}\text { Attractiveness: Women gave } \\
\text { attractiveness ratings of frontal and } \\
\text { lateral facial photographs }\end{array}$ & $\begin{array}{l}\text { Composite sperm index derived } \\
\text { from sperm concentration, } \\
\text { percentage of motile sperm, and } \\
\text { percentage of normal } \\
\text { morphology }\end{array}$ & $F=30.7^{* *}$ & $\begin{array}{l}\text { Women rated long-term } \\
\text { sexual attraction } \\
\text { Facial width, a measure of } \\
\text { facial masculinity, } \\
\text { negatively correlated with } \\
\text { the sperm quality index }\end{array}$ \\
\hline Soler et al. (2003) & $\begin{array}{l}\text { Neubauer haemocytometer } \\
\text { (2.7) years }\end{array}$ & $\begin{array}{l}\text { Attractiveness: Women gave } \\
\text { attractiveness ratings of frontal and } \\
\text { lateral facial photographs }\end{array}$ & $\begin{array}{l}\text { Sperm concentration } \\
\text { Percentage of motile sperm } \\
\text { Percentage of morphologically } \\
\text { normal sperm } \\
\text { Composite index of semen } \\
\text { quality }\end{array}$ & $\begin{array}{l}r=0.026 \\
r=0.325^{*} \\
r * * \\
r=0.295^{*}\end{array}$ \\
\hline $\begin{array}{l}\text { Neubauer haemocytometer } \\
\text { attractiveness as a } \\
\text { permanent partner }\end{array}$
\end{tabular}

